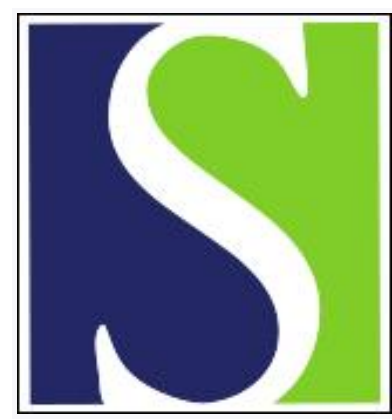

Scand J Work Environ Health 2012;38(4):349-357

https://doi.org/10.5271/sjweh.3295

Published online: 30 Mar 2012, Issue date: 01 Jul 2012

Gender differences in the effect of weekly working hours on occupational injury risk in the United States working population

by Wirtz A, Lombardi DA, Willetts JL, Folkard S, Christiani DC

Affiliation: Department of Environmental Health, Harvard School of Public Health, Landmark Center, 3-49-7, 401 Park Drive, Boston, MA 02215, USA. awirtz@hsph.harvard.edu

Refers to the following texts of the Journal: 1996;22(2):124-132 2006;32(1):32-40 2006;32(6):502-514 2007;33(5):344-350 2011;37(1):54-61

The following articles refer to this text: 2018;44(4):341-350; 2019;45(2):166-173

Key terms: epidemiology; gender; gender difference; occupational injury; occupational safety; sleep; United States; weekly working hour; woman; work hour; working population

This article in PubMed: www.ncbi.nlm.nih.gov/pubmed/22466526 


\title{
Gender differences in the effect of weekly working hours on occupational injury risk in the United States working population
}

\author{
by Anna Wirtz, PhD, ${ }^{1,2}$ David A Lombardi, PhD, ${ }^{1,2}$ Joanna L Willetts, MS, ${ }^{2}$ Simon Folkard, PhD, DSc, ${ }^{3,4}$ \\ David C Christiani, MD ${ }^{1}$
}

\begin{abstract}
Wirtz A, Lombardi DA, Willetts JL, Folkard S, Christiani DC. Gender differences in the effect of weekly working hours on occupational injury risk in the United States working population. Scand $J$ Work Environ Health. 2012;38(4):349-357. doi:10.5271/sjweh.3295
\end{abstract}

\begin{abstract}
Objectives Long working hours can lead to an accumulation in fatigue that may increase worker's risk of injury. However, it is not known if this association is different for men and women. Our aim was, therefore, to investigate gender differences in the effect of weekly working hours on occupational injury risk.

Methods The US National Health Interview Survey is a clustered, stratified, cross-sectional sample representative of the US population, collected using in-household interviews. We pooled seven years of data (2004-2010) comprising 96915 employed workers. Annualized injury rates per 100 workers were estimated for men and women in categories of weekly working hours $(<30,31-40,41-50,>50$ hours/week). Additionally, injury risk was predicted using weighted logistic regression models by weekly working hour categories, stratified by gender, including age, ethnicity, education, type of pay, occupation, body mass index, usual sleep duration, and psychological distress as covariates.

Results Of 96915 workers, $705(0.75 \%)$ reported an injury in the last 3 months. Injury rates were higher among men and increased with increasing working hours for both genders. However, results of the adjusted logistic regression model indicated an interactive effect of working hours and gender on injury risk [odds ratio (OR) $1.02,95 \%$ confidence interval $(95 \%$ CI) $1.00-1.03)$. Injury risk increased among women working $41-50$ hours/week (OR 1.51, 95\% CI 1.03-2.21) and >50 hours/week (OR 1.69, 95\% CI 1.06-2.70) compared to 31-40 hours/week but not among men.
\end{abstract}

Conclusions The findings indicate an increase in injury risk with increasing working hours among women but not men.

Key terms epidemiology; occupational safety; sleep; woman; work hour.

The average number of hours worked per week has increased by about one hour in the United States during the last two decades, a pattern of work style contrary to other economies, eg, the European Union and Japan where weekly hours have declined by about two and five hours, respectively, over the same time period (1). Extending hours of work inevitably leads to a reduction in time for recovery from work-related fatigue and sleep during rest periods (2), as well as an increase in exposure time to occupational strains and work conditions that are potentially hazardous. As a consequence, performance deteriorates, and the risk of errors and injuries or "accidents" on the job increases (3-8). Thus, a growing base of empirical evidence indicates a negative impact of long working hours on employees' safety (9-12).

Additionally, individual factors (eg, demographic characteristics, mental health, and health-related measures, such as obesity or physical fitness) and workrelated characteristics (eg, physical demands) are associated with weekly working hours $(5,13-16)$ and at the same time influence occupational injury risk (14, 17-24). These factors might thus confound the relation between working hours and injury risk.

Among demographic factors, work schedule design

1 Department of Environmental Health, Harvard School of Public Health, Boston, MA, USA.

2 Center for Injury Epidemiology, Liberty Mutual Research Institute for Safety, Hopkinton, MA, USA.

3 Université Paris Descartes, Institut de Psychologie, Paris, France.

4 Body Rhythms and Shiftwork Centre, University of Wales Swansea, Swansea, UK.

Correspondence to: Anna Wirtz, Department of Environmental Health, Harvard School of Public Health, Landmark Center, 3-49-7, 401 Park Drive, Boston, MA 02215, USA. [E-mail: awirtz@hsph.harvard.edu] 
has been associated with different effects on occupational injury risk among men and women. While men generally show higher injury rates than women, women appear to have a greater risk while working on weekends and are more likely to experience an injury when working in rotating shifts $(25,26)$. On the other hand, results of a recent study based on the Canadian population indicate that the increase in injury risk across weekly working hours is slightly stronger among men than women (23). However, this study did not control for sleep effects.

Women still work substantially longer hours undertaking household and related activities compared to men $(27,28)$ and spend more time away from work due to domestic responsibilities (29). Thus, time for recovery and sleep might be decreased, elevating the fatigue-related impact of longer working hours among women. This has been supported by studies demonstrating reduced work ability (28) and higher musculoskeletal disorders (30) among women working longer hours combined with domestic workload. However, there is a lack of research regarding gender differences in the association between long working hours and safety, and only few studies have used large samples or nationally representative data sources to examine these relationships and included possible confounding factors, such as sleep.

The aim of the current study was, therefore, to examine gender differences in the risk of occupational injury across weekly working hours in a large sample of workers in the US, using pooled data from the National Health Interview Survey (NHIS) over seven years (2004-2010) while controlling for several potential individual and work-related confounding factors. We hypothesized that long work hours are related to a higher injury risk among women than men, implying an interactive effect between weekly working hours and gender.

\section{Methods}

\section{Study sample}

The NHIS is a publicly available, multistage, clustered, stratified, cross-sectional sample representative of the US population. It is collected every year using inhousehold interviews and is considered to be a source for detailed information about the health status, health behavior, and healthcare access and utilization in the US (31). The complex sample design allows for valid population estimates, when accounting for the stratification, clustering, and weighting in the study design $(32,33)$.

Of all interviewed individuals in the "household component" of the survey ( $\mathrm{N}=597247)$, we included persons aged 18-74 years who reported working for pay ("employed") and gave information about their weekly work hours in the previous week ( $\mathrm{N}=249$ 713). Information about most covariates were collected in the "adult core" sample (containing information of one randomly sampled adult within the family), further reducing the sample size to $\mathrm{N}=103773$. Due to missing covariate information, 6858 individuals were excluded, resulting in a final sample size of $\mathrm{N}=96915$ for the estimation of multivariable injury risk prediction models.

\section{Case definition of occupational injury}

A person was classified as "injured" if they reported at least one injury or poisoning episode that required medical attention during the three months prior to the interview $(32,33)$. Only work-related injuries were used in the analyses, as determined by the answer "working at a paid job" in response to the question "What were you doing when the injury happened?".

\section{Weekly working hours}

Within the "family component", each employed individual reported their weekly working hours in the last week, which was measured on a continuous scale, and subsequently categorized a priori into $\leq 30,31-40,41-50$, and $>50$ hours per week and used as the independent variable.

\section{Sociodemographic, work-related, and health factors}

Several sociodemographic factors were included as control variables in the analysis (eg, age, education, and ethnicity). Education was defined as the highest education achieved ["did not complete high school", "high school graduate" (reference category), "some college", "bachelor's degree", "master's degree", and "professional school degree or doctoral degree"], and ethnicity was available as a categorical variable classified into "non-hispanic white" (reference category), "hispanic", "non-hispanic black", and "non-hispanic other".

To account for work-related influences on work hours and injury risk, information about occupation (a priori coded according to the Standard Occupation Classification; the reference category was "office and administrative support") and type of pay (in response to the question "Were you paid hourly?", reference category "no") were included in the analysis.

Previous studies indicated that short sleep, higher body mass index (BMI), and impairments in mental health are associated with long work hours $(5,15,16$, $34)$ and increased injury risk $(24,35)$, and these variables were therefore included as covariates. Usual daily sleep duration in hours was measured in response to the question "On average, how many hours of sleep do you get in a 24-hour period?". BMI was computed from selfreported height and weight. Mental health was measured 
using a scale developed and validated for use in the NHIS containing 6 questions "During the past 30 days, how often did you feel ...": (i) so sad that nothing could cheer you up?; (ii) nervous; (iii) restless or fidgety; (iv) hopeless; (v) that everything was an effort; (vi) worthless. All were answered on a 5-point scale from "never" to "all of the time", and the item scores from all 6 questions were added to achieve an overall sum score, ranging from $0-24$, called the K6 score, indicating the level of psychological distress (36).

\section{Statistical analysis}

Weighted frequencies and means for all variables were calculated by gender, adjusted for the weighting, clustering, and stratification in the NHIS.

Weighted annualized injury rates per 100 workers across weekly work hour categories $(\leq 30,31-40$, $41-50$, and $>50$ hours/week) were estimated based on the sample containing information on weekly working hours and occupational injury ( $\mathrm{N}=249713)$ for the total sample and stratified by gender.

To estimate the risk of an occupational injury (as a dichotomous variable) across weekly working hours [as a categorical variable with full-time work (31-40 hours/week) as the reference category), weighted logistic regression analyses were used, with and without adjustment for all covariates, with $\mathrm{P}<0.05$ as the level of significance. The analyses were stratified by gender to estimate the effects of weekly working hours on injury risk for men and women separately. To test a potential interaction of gender and working hours, a second logistic regression model was estimated using the total sample and including gender and the interaction term "work hours $\times$ gender" in addition to the covariate set described above. To test gender differences within work hour categories, a third adjusted logistic regression model was estimated to predict injury risk for women versus men, stratified by working hour categories. All analyses were conducted with SAS version 9.2 (SAS Institute, Cary, NC, USA) procedures for survey data, and the sample weights provided by the NHIS were used for all analyses.

The institutional review boards of the Harvard School of Public Health and the Liberty Mutual Research Institute for Safety approved this study.

\section{Results}

\section{Sample description}

The sub sample containing all covariate information $(\mathrm{N}=96$ 915) included 48816 (51.4\%) men and 48099 (48.6\%) women, with a total of 705 injured workers
$(0.75 \%)$. The detailed sample description and distributions of all variables are presented in table 1 .

Comparison among men and women showed that the proportion of occupational injury was substantially higher among men $(0.95 \%)$ than women $(0.53 \%)$ and that men worked significantly longer (mean 42.6 hours/ week) than women (mean 37.3 hours/week, $\mathrm{P}<0.05$ ). Women reported slightly longer sleep duration, higher proportion of hourly payment, and a higher level of psychological distress than men. As expected, the distribution of men and women differed also by occupational category (see table 1).

\section{Unadjusted annualized injury rates}

An estimated 3428402 work-related injury episodes occurred annually over the 7-year study period, with approximately 130 million estimated workers per year at risk, leading to an incidence of 2.65 injuries per 100 workers (see table 2). While men generally showed higher unadjusted annualized injury rates than women, the injury rates increased across the a priori defined categories of weekly work hours for both groups and the total sample. One exception was a higher injury rate among men working $<30$ hours/week compared to 31-40 hours/week.

\section{Weekly work hours and injury risk in men and women}

Estimating the injury risk across weekly working hours in an unadjusted logistic regression model revealed an increased risk for men working 41-50 hours/week (OR 1.23, 95\% CI 1.03-1.47) and >50 hours/week (OR $1.34,95 \%$ CI $1.11-1.62$ ) compared to $31-40$ hours/ week, whereas the category $<30$ hours/week did not show any significant difference (OR 1.14, 95\% CI $0.90-1.46)$. A similar trend was found for women, who had an increased injury risk when working 41-50 hours/ week (OR 1.35, 95\% CI 1.03-1.77) and $>50$ hours/ week (OR 1.53, 95\% CI 1.08-2.16) compared to 31-40 hours/week, but not $<30$ hours/week (OR 0.95, 95\% CI $0.73-1.24)$.

Results of the adjusted logistic regression analyses (see table 3 ) showed that, among women, working 41-50 and $>50$ hours/week was associated with an increased injury risk compared to 31-40 hours/week while controlling for all covariates. For men, we did not find any significant increase in injury risk in any work hour category compared to $31-40$ hours/week in the adjusted model. The interaction term "working hours $\times$ gender" was statistically significant $(\mathrm{P}=0.02)$ in the overall logistic regression model, which included all covariates.

A linear trend was fitted to the OR for injury risk across working hour categories, and variance explained $\left(\mathrm{R}^{2}\right)$ by this linear trend was compared between men 
Table 1. Description of the National Health Interview Survey (NHIS) 2004-2010 sub sample containing all covariate information by gender ( $\mathrm{N}=96$ 915). [SE=standard error]

\begin{tabular}{|c|c|c|c|c|c|c|c|c|}
\hline \multirow[t]{2}{*}{ Characteristic } & \multicolumn{4}{|c|}{ Men } & \multicolumn{4}{|c|}{ Women } \\
\hline & $\begin{array}{c}\mathrm{N} \\
\text { (interviewed) }\end{array}$ & $\begin{array}{c}\% \\
\text { (weighted) }\end{array}$ & Mean & SE & $\begin{array}{c}\mathrm{N} \\
\text { (interviewed) }\end{array}$ & $\begin{array}{c}\% \\
\text { (weighted) }\end{array}$ & Mean & SE \\
\hline Age & 48816 & & 40.82 & 0.10 & 48099 & & 41.22 & 0.10 \\
\hline \multicolumn{9}{|l|}{ Education } \\
\hline Did not complete high school & 6899 & 11.22 & & & 4943 & 7.85 & & \\
\hline High school graduate & 12977 & 26.45 & & & 12036 & 24.51 & & \\
\hline Some college & 14106 & 29.73 & & & 16257 & 34.65 & & \\
\hline Bachelor's degree & 9749 & 21.54 & & & 9824 & 21.74 & & \\
\hline Master's degree & 3390 & 7.37 & & & 4015 & 8.96 & & \\
\hline Professional school degree & 1695 & 3.69 & & & 1024 & 2.30 & & \\
\hline \multicolumn{9}{|l|}{ Ethnicity } \\
\hline Hispanic & 9986 & 13.22 & & & 8311 & 10.36 & & \\
\hline Non-hispanic white & 29999 & 71.64 & & & 28831 & 71.26 & & \\
\hline Non-hispanic black & 5875 & 10.24 & & & 8284 & 13.87 & & \\
\hline Non-hispanic other & 2956 & 4.90 & & & 2673 & 4.50 & & \\
\hline \multicolumn{9}{|l|}{ Occupation } \\
\hline Management & 5090 & 11.16 & & & 3498 & 7.65 & & \\
\hline Education, training, and library & 1503 & 3.23 & & & 4289 & 9.51 & & \\
\hline Healthcare practitioners and technical & 1179 & 2.47 & & & 3955 & 8.64 & & \\
\hline Food preparation and serving-related & 2133 & 4.08 & & & 3026 & 6.25 & & \\
\hline Building and grounds cleaning and maintenance & 2279 & 4.13 & & & 2021 & 3.38 & & \\
\hline Sales and related & 4814 & 10.51 & & & 5276 & 10.97 & & \\
\hline Office and administrative support & 3339 & 6.75 & & & 10155 & 21.42 & & \\
\hline Construction and extraction & 5518 & 10.54 & & & 139 & 0.28 & & \\
\hline Production & 4363 & 8.57 & & & 2271 & 4.16 & & \\
\hline Transportation and material moving & 4569 & 8.86 & & & 1015 & 1.96 & & \\
\hline Other a & 14029 & 29.71 & & & 12454 & 25.78 & & \\
\hline \multicolumn{9}{|l|}{ Paid Hourly } \\
\hline No & 21770 & 46.41 & & & 17723 & 38.26 & & \\
\hline Yes & 27046 & 53.59 & & & 30376 & 61.74 & & \\
\hline \multicolumn{9}{|l|}{ Weekly working hours } \\
\hline$\leq 20$ hours & 3162 & 3.38 & & & 5919 & 6.23 & & \\
\hline $21-30$ hours & 2912 & 3.10 & & & 5301 & 5.39 & & \\
\hline $31-40$ hours & 25050 & 25.33 & & & 26862 & 26.35 & & \\
\hline $41-50$ hours & 9960 & 11.09 & & & 6459 & 6.84 & & \\
\hline $51-60$ hours & 5189 & 5.73 & & & 2469 & 2.57 & & \\
\hline$>60$ hours & 2543 & 2.82 & & & 1089 & 1.17 & & \\
\hline Mean weekly working hours & 48816 & & 42.62 & 0.08 & 48099 & & 37.35 & 0.08 \\
\hline Usual sleep duration/24 hours & 48816 & & 6.97 & 0.01 & 48099 & & 7.04 & 0.01 \\
\hline Body mass index $\left(\mathrm{kg} / \mathrm{m}^{2}\right)$ & 48816 & & 27.73 & 0.03 & 48099 & & 26.94 & 0.04 \\
\hline Psychological distress ${ }^{b}$ & 48816 & & 1.78 & 0.02 & 48099 & & 2.34 & 0.02 \\
\hline \multicolumn{9}{|l|}{ Injured } \\
\hline No & 48374 & 99.05 & & & 47836 & 99.47 & & \\
\hline Yes & 442 & 0.95 & & & 263 & 0.53 & & \\
\hline \multicolumn{9}{|l|}{ Injured cases in weekly working hour categories } \\
\hline$\leq 30$ hours & 61 & 0.13 & & & 49 & 0.10 & & \\
\hline $31-40$ hours & 212 & 0.44 & & & 137 & 0.27 & & \\
\hline $41-50$ hours & 100 & 0.22 & & & 46 & 0.10 & & \\
\hline$>50$ hours & 69 & 0.16 & & & 31 & 0.06 & & \\
\hline
\end{tabular}

a Other occupations include business and finance; installation, maintenance and repair; personal care and service; computer and mathematics; healthcare support; protective service; arts design, entertainment, sports, and media; architecture and engineering; community and social services; legal; life, physical, and social science; farming, fishing, and forestry; military-specific.

${ }^{\circ}$ Sum of 6 items, $0=$ minimum, 24=maximum. 
Table 2. Estimated annualized work-related injury incidence per 100 workers by weekly hours worked in the US National Health Interview Survey (NHIS) (2004-2010) for the total sample and by gender.

\begin{tabular}{|c|c|c|c|c|c|}
\hline Hours worked per week & $\begin{array}{l}\text { Average number of } \\
\text { hours worked }\end{array}$ & $\begin{array}{l}\text { Number of workers } \\
\text { interviewed }\end{array}$ & $\begin{array}{l}\text { Estimated number of } \\
\text { annual work-related } \\
\text { injuries }\end{array}$ & $\begin{array}{l}\text { Estimated number of } \\
\text { workers annually }\end{array}$ & $\begin{array}{c}\text { Estimated annual } \\
\text { incidence per } 100 \\
\text { workers }^{\text {a }}\end{array}$ \\
\hline \multicolumn{6}{|l|}{ Total sample } \\
\hline$\leq 30$ hours & 20.6 & 42208 & 510899 & 22343643 & 2.29 \\
\hline $31-40$ hours & 39.2 & 141619 & 1679628 & 70742804 & 2.37 \\
\hline $41-50$ hours & 47.4 & 38902 & 690939 & 21494769 & 3.21 \\
\hline$>50$ hours & 62.4 & 26984 & 546937 & 14985031 & 3.65 \\
\hline Total & 40.1 & 249713 & 3428402 & 129566248 & 2.65 \\
\hline \multicolumn{6}{|l|}{ Men } \\
\hline$\leq 30$ hours & 20.9 & 15480 & 290998 & 8329446 & 3.49 \\
\hline $31-40$ hours & 39.5 & 72370 & 1116947 & 36531864 & 3.06 \\
\hline $41-50$ hours & 47.6 & 24811 & 522564 & 13892874 & 3.76 \\
\hline$>50$ hours & 62.7 & 19319 & 443025 & 10835523 & 4.09 \\
\hline Total & 42.5 & 131980 & 2373534 & 69589707 & 3.41 \\
\hline \multicolumn{6}{|l|}{ Women } \\
\hline$\leq 30$ hours & 20.5 & 26728 & 219901 & 14014197 & 1.57 \\
\hline $31-40$ hours & 39.0 & 69249 & 562681 & 34210940 & 1.64 \\
\hline $41-50$ hours & 47.1 & 14091 & 168375 & 7601895 & 2.21 \\
\hline$>50$ hours & 61.8 & 7665 & 103911 & 4149508 & 2.50 \\
\hline Total & 37.3 & 117733 & 1054868 & 59976541 & 1.76 \\
\hline
\end{tabular}

a Includes individuals reporting employment at a job or business and those who had reported weekly work hours

and women: for women, $\mathrm{R}^{2}$ was $97 \%$ whereas for men it was $43 \%$. This did not change significantly when an exponential trend was fitted; however, the exponential fit showed a steeper slope among women than men (data not shown).

To compare the risk for women and men in each working hour category, the adjusted logistic regression model was stratified by work hour categories. The resulting adjusted risk estimates for women compared to men were: (i) <30 hours/week: OR $0.44(95 \% \mathrm{CI}$ 0.29-0.67); (ii) 31-40 hours/week: OR 0.60 (95\% CI 0.46-0.79); (iii) 41-50 hours/week: OR 0.73 (95\% CI 0.45-1.19); and (iv) >50 hours/week: OR 0.87 (95\% CI 0.49-1.52). Thus, men generally showed a higher injury risk in all work hour categories, but women differed only with regard to their risk in categories of $<40$ hours/ week. With increasing working hours, the injury risk for women approached the male level and did not differ significantly from men in the categories $>40$ hours/week.

\section{Discussion}

The results of this study showed an increase in injury rates per 100 workers across weekly working hours for men and women. While injury rates and risk were generally higher among men than women, as expected, an increase in injury risk with increasing weekly working hours was found only for women when controlling for all covariates in multivariable weighted logistic regression. This was supported by the variance explained in a linear trend fitted to the risk estimates.
Additionally, a direct comparison within each work hour category showed that injury risk was significantly higher among men than women working $\leq 40$ hours/ week; however, the trend in risk for women approached the male risk level in categories $>40$ hours/week due to a stronger risk increase with increasing work hours among women. Thus, the results show the tendency that working hours have an effect on injury risk only for women, which diminishes the differences in injury risk between men and women in long working hours. The relatively stronger impact of working hours on injury risk in women might at least partially be due to the potentially higher burden of household and related activities for women $(27,28)$, which would further decrease time for recovery and sleep, elevating the fatigue-related impact of long working hours. Previous findings supported this relationship, demonstrating a negative impact of combined long domestic and work hours on work ability and musculoskeletal impairments among women but not men $(28,30)$. Another study reported a curvilinear relationship between work hours and the need for recovery among men but a linear relationship among women (37). The injury rates in the present study showed a slightly similar distribution, although not statistically significant. On the other hand, short sleep increased injury risk among men but not women, and women slept slightly longer than men in the present study. Thus, the causal mechanisms of long domestic and working hours, sleep duration, recovery opportunities, and fatigue among men and women should be investigated in future studies.

The findings presented are in theoretical accordance with previous results indicating that women seem to be more vulnerable to detrimental effects of work sched- 
Table 3. Prediction of injury risk by weekly hours worked, multivariable weighted logistic regression, adjusted odds ratio estimates (OR) with $95 \%$ confidence intervals $(95 \% \mathrm{Cl})$.

\begin{tabular}{|c|c|c|c|c|c|c|c|c|c|}
\hline \multirow[t]{2}{*}{ Parameter } & \multicolumn{3}{|c|}{ Men } & \multicolumn{3}{|c|}{ Women } & \multicolumn{3}{|c|}{ Total } \\
\hline & $\begin{array}{l}\text { Parameter } \\
\text { estimate }\end{array}$ & OR & $95 \% \mathrm{Cl}$ & $\begin{array}{l}\text { Parameter } \\
\text { estimate }\end{array}$ & OR & $95 \% \mathrm{Cl}$ & $\begin{array}{l}\text { Parameter } \\
\text { estimate }\end{array}$ & OR & $95 \% \mathrm{Cl}$ \\
\hline \multicolumn{10}{|l|}{ Work hours a } \\
\hline$\leq 30$ hours & 0.03 & 1.03 & $0.74-1.45$ & -0.31 & 0.74 & $0.51-1.07$ & -0.12 & 0.89 & $0.69-1.15$ \\
\hline $31-40$ hours & Reference & & & Reference & & & Reference & & \\
\hline $41-50$ hours & 0.19 & 1.21 & $0.92-1.58$ & $0.41^{b}$ & 1.51 & $1.03-2.21$ & $0.26^{b}$ & 1.30 & $1.05-1.61$ \\
\hline$>50$ hours & 0.12 & 1.12 & $0.80-1.57$ & $0.52^{b}$ & 1.69 & $1.06-2.70$ & 0.23 & 1.26 & $0.96-1.65$ \\
\hline Sleep hours & $-0.14^{b}$ & 0.87 & $0.78-0.97$ & -0.04 & 0.96 & $0.85-1.09$ & $-0.10^{b}$ & 0.90 & $0.84-0.98$ \\
\hline Age & $-0.01^{b}$ & 0.99 & $0.98-1.00$ & 0.01 & 1.01 & $1.00-1.02$ & $-0.01^{b}$ & 0.99 & $0.99-1.00$ \\
\hline \multicolumn{10}{|l|}{ Education } \\
\hline Did not complete high school & -0.03 & 0.97 & $0.68-1.37$ & 0.17 & 1.19 & $0.71-1.99$ & 0.02 & 1.02 & $0.76-1.37$ \\
\hline High school & Reference & & & Reference & & & Reference & & \\
\hline Some college & 0.25 & 1.28 & $0.99-1.66$ & 0.16 & 1.18 & $0.84-1.65$ & $0.21^{b}$ & 1.24 & $1.02-1.51$ \\
\hline Bachelor's degree & -0.32 & 0.72 & $0.48-1.09$ & -0.09 & 0.92 & $0.55-1.54$ & -0.24 & 0.78 & $0.57-1.07$ \\
\hline Master's degree & $-0.83^{b}$ & 0.43 & $0.20-0.95$ & -0.51 & 0.60 & $0.29-1.24$ & $-0.69 b$ & 0.50 & $0.30-0.85$ \\
\hline $\begin{array}{l}\text { Professional school / doctoral } \\
\text { degree }\end{array}$ & -1.05 & 0.35 & $0.08-1.45$ & -0.32 & 0.73 & $0.21-2.46$ & -0.79 & 0.45 & $0.18-1.15$ \\
\hline \multicolumn{10}{|l|}{ Ethnicity } \\
\hline White & Reference & & & Reference & & & Reference & & \\
\hline Hispanic & -0.21 & 0.81 & $0.60-1.09$ & $-0.46^{b}$ & 0.63 & $0.40-0.98$ & $-0.31^{b}$ & 0.74 & $0.58-0.94$ \\
\hline Non-Hispanic Black & -0.16 & 0.85 & $0.62-1.18$ & -0.10 & 0.90 & $0.64-1.26$ & -0.16 & 0.85 & $0.69-1.06$ \\
\hline Other & $-0.83 b$ & 0.44 & $0.23-0.83$ & -0.30 & 0.74 & $0.34-1.62$ & $-0.63^{b}$ & 0.53 & $0.32-0.88$ \\
\hline Body mass index ${ }^{c}$ & 0.01 & 1.01 & $0.99-1.03$ & $0.02^{b}$ & 1.03 & $1.01-1.04$ & $0.02^{b}$ & 1.02 & $1.00-1.03$ \\
\hline \multicolumn{10}{|l|}{ Occupation } \\
\hline Management & -0.03 & 0.98 & $0.51-1.86$ & -0.19 & 0.83 & $0.37-1.87$ & -0.04 & 0.97 & $0.61-1.52$ \\
\hline Education, training, and library & 0.62 & 1.85 & $0.81-4.22$ & $0.75^{b}$ & 2.11 & $1.15-3.87$ & $0.75^{b}$ & 2.11 & $1.31-3.40$ \\
\hline $\begin{array}{l}\text { Healthcare practitioners and } \\
\text { technical }\end{array}$ & 0.79 & 2.20 & $0.81-6.00$ & $0.76^{b}$ & 2.13 & $1.25-3.62$ & $0.76^{b}$ & 2.14 & $1.35-3.38$ \\
\hline Food preparation and serving-related & 0.07 & 1.07 & $0.52-2.21$ & $0.64^{b}$ & 1.90 & $1.06-3.40$ & 0.37 & 1.45 & $0.92-2.31$ \\
\hline $\begin{array}{l}\text { Building and grounds cleaning and } \\
\text { maintenance }\end{array}$ & 0.56 & 1.75 & $0.90-3.39$ & 0.73 & 2.08 & $0.94-4.61$ & $0.66^{b}$ & 1.93 & $1.19-3.12$ \\
\hline Sales and related & -0.06 & 0.94 & $0.48-1.85$ & 0.11 & 1.11 & $0.64-1.94$ & 0.03 & 1.03 & $0.67-1.61$ \\
\hline Office and administrative support & Reference & & & Reference & & & Reference & & \\
\hline Construction and extraction & $0.87^{b}$ & 2.39 & $1.42-4.02$ & 0.62 & 1.86 & $0.42-8.22$ & $0.96^{b}$ & 2.62 & $1.82-3.77$ \\
\hline Production & $0.79 b$ & 2.21 & $1.26-3.86$ & $0.70^{b}$ & 2.00 & $1.09-3.68$ & $0.84^{b}$ & 2.31 & $1.58-3.37$ \\
\hline Transportation and material moving & 0.44 & 1.55 & $0.92-2.59$ & $0.88^{b}$ & 2.41 & $1.14-5.09$ & $0.57^{b}$ & 1.76 & $1.20-2.59$ \\
\hline Other ${ }^{d}$ & 0.22 & 1.25 & $0.76-2.07$ & 0.37 & 1.44 & $0.93-2.23$ & $0.31^{b}$ & 1.36 & $0.99-1.88$ \\
\hline \multicolumn{10}{|l|}{ Paid hourly } \\
\hline No & Reference & & & Reference & & & Reference & & \\
\hline Yes & $0.51^{\mathrm{b}}$ & 1.67 & $1.26-2.21$ & $0.53^{b}$ & 1.70 & $1.21-2.40$ & $0.53^{b}$ & 1.69 & $1.37-2.08$ \\
\hline Psychological distress (K6 score) e & $0.06^{b}$ & 1.06 & $1.04-1.09$ & $0.07^{b}$ & 1.08 & $1.05-1.10$ & $0.07^{b}$ & 1.07 & $1.05-1.09$ \\
\hline Weekly working hours (continuous) ${ }^{\dagger}$ & & & & & & & 0.00 & 1.00 & $0.99-1.01$ \\
\hline \multicolumn{10}{|l|}{ Gender $^{f}$} \\
\hline Male & & & & & & & Reference & & \\
\hline Female & & & & & & & $-1.11^{b}$ & 0.33 & $0.20-0.56$ \\
\hline Work hours $\times$ gender $^{f}$ & & & & & & & $0.02^{b}$ & 1.02 & $1.00-1.03$ \\
\hline
\end{tabular}

a In the total sample, estimates for weekly work hour categories are presented based on a model without the interaction term "work hours $\times$ gender".

b $P<0.05$

c Continuous variable $\left(\mathrm{kg} / \mathrm{m}^{2}\right)$.

d Other occupations include business and finance; installation, maintenance and repair; personal care and service; computer and mathematics; health-

care support; protective service; arts design, entertainment, sports, and media; architecture and engineering; community and social services; legal; life, physical, and social science; farming, fishing, and forestry; military-specific.

e Continuous variable, $0=$ minimum, 24=maximum.

${ }^{f}$ Variables included in analysis of the total sample only. 
uling on occupational injury risk, shown in studies on rotating / irregular shifts $(26,38)$. Conversely, our results are not consistent with a Canadian study, in which injury risk was higher among men than women when working long hours (23). However, a different categorization of weekly hours worked was used in the Canadian study, and substantial differences between men and women were detected in very long hours only ( $>80$ hours/week), which leads to questions about the number of injured cases in these groups, especially for women. Furthermore, the authors did not account for sleep and individual health-related factors, which can alter the relation between weekly working hours and injury risk substantially (12).

However, men working short hours showed higher injury rates per 100 workers and a slightly but not significant higher injury risk than men working 31-40 hours/week. This might be related to different occupational risk factors among men and women, or a higher proportion of health impairments among men with short working hours (workers with health impairments might choose shorter working hours), as indicated by previous findings (37). Thus, these factors related to injury risk need to be studied further within this subgroup.

\section{Limitations and strengths}

Limitations of our study include the cross-sectional design and the use of subjective self-reported data, which could potentially lead to recall bias, effects of social desirability, and other shortcomings of subjective reports. Injury reports during the last 3 months were used as the outcome, which may have led to underreporting, since injury recall accuracy is considered to decrease with increasing elapsed time since the injury, and might be better for more serious injuries $(39,40)$. Using a shorter reference period (eg, 5 weeks) as suggested by Warner et al (40) could have improved recall, but at the same time it would have limited the number of injuries and, thus, the statistical power for the analyses. However, we do not expect a systematic recall error in that those with longer working hours had a better recall for earlier or more serious injuries. On the other hand, a bias towards less serious injuries might have occurred, because it is possible that those individuals having experienced a serious injury in the last 3 months, which caused long-term work disability, might not have returned to work yet. Thus, they might not report having worked in the last week, and were therefore not included in the analysis. This would lead to an underestimation of the effect estimates for weekly working hours if longer hours were associated with more serious injuries.

The independent variable was measured by reports about the number of working hours in the last week, which did not capture the work schedule at the time of the injury, or differences over time, and did not allow for an estimation of injury risk across shifts worked or across accumulated working time. Furthermore, the NHIS did not provide additional information about the work schedule, such as shift work, night work, irregular working hours, or rest breaks, which would have been important as potential risk factors for occupational injury since in 2004, about $17.7 \%$ of the US workforce usually worked alternate shifts (41). Furthermore, differences in injury risk between men and women might be task-related, and this study could only provide limited control over these factors by including occupation and type of pay as indicators for job-related exposures and probably also for shift work.

On the other hand, this study had several strengths. While previous studies have shown an increase in injury risk across weekly working hours $(9,10,42)$, this study is the first to use a nationally representative sample to investigate gender differences in the association between injury risk and working hours in the US. A major strength of this study is that the use of data from the NHIS, a large clustered and stratified sample, allowed for the estimation of weighted outcomes, which were representative of the US working population. Thus, the external validity of the results is high. By pooling the data over 7 years, this study is one of the first to conduct injury prediction stratified by gender, which had not been possible in previous studies on long working hours and injury risk in the US. However, despite the large sample size, the number of injured cases was limited in long work hour categories, leading to lower statistical power in these categories. Another strength of the study is that we adjusted our risk estimation for several potential confounding variables, such as demographic characteristics, work-related and individual factors, such as psychological distress and the usual amount of sleep, which are important injury risk factors and have not been accounted for in previous analyses of the effects of working hours on injury risk in men and women.

In conclusion, findings from a representative sample of the US workforce indicated a higher injury risk among men than women, as expected. However, an increase in injury risk with increasing weekly working hours was found for women but not men. Thus, women seemed to approach the male injury risk level when working longer hours. These results are therefore a first indicator that women potentially may be more vulnerable to the negative impact of long work hours on occupational injury risk than men, while being at lower risk in short working hours. However, further research is needed to validate these findings and examine potential different injury mechanisms related to work hours and fatigue among men and women while taking into account exposures to occupational risk factors, a priori risks, and recovery opportunities from work-related strains. This might pro- 
vide valuable information to identify vulnerable cohorts and develop targeted injury prevention strategies, eg, in occupations where women work longer hours than men.

\section{Acknowledgements}

Dr. Anna Wirtz was funded by a Liberty Mutual-Harvard School of Public Health Postdoctoral Fellowship. The authors would like to thank Dr. Helen Marucci-Wellman, Dr. Mary Lesch, and Theodore Courtney from the Liberty Mutual Research Institute for Safety for their insightful and constructive comments on earlier versions of the manuscript.

\section{References}

1. Demetriades S, Pedersini R. Working time in the EU and other global economies. Luxembourg: Office for Official Publications of the European Communities; 2008.

2. Härmä M. Workhours in relation to work stress, recovery and health. Scand J Work Environ Health. 2006;32:502-14. http:// dx.doi.org/10.5271/sjweh.1055.

3. Akerstedt T, Folkard S, Portin C. Predictions from the three-process model of alertness. Aviat Space Environ Med. 2004; 75:A75-83.

4. Binnewies C, Sonnentag S, Mojza EJ. Daily performance at work: feeling recovered in the morning as a predictor of daylevel job performance. J Organ Behav. 2009;30:67-93. http:// dx.doi.org/10.1002/job.541.

5. Proctor SP, White RF, Robins TG, Echeverria D, Rocskay AZ. Effect of overtime work on cognitive function in automotive workers. Scand J Work Environ Health. 1996;22:124-32. http://dx.doi.org/10.5271/sjweh.120.

6. Sallinen M, Holm J, Hirvonen K, Härmä M, Koskelo J, Letonsaari $\mathrm{M}$, et al. Recovery of cognitive performance from sleep debt: do a short rest pause and a single recovery night help? Chronobiol Int. 2008;25:279-96. http://dx.doi. org/10.1080/07420520802107106.

7. Swaen GM, Van Amelsvoort LG, Bultmann U, Kant IJ. Fatigue as a risk factor for being injured in an occupational accident: results from the Maastricht Cohort Study. Occup Environ Med. 2003;60 Suppl 1:i88-92. http://dx.doi.org/10.1136/oem.60. suppl_1.i88.

8. Williamson A, Lombardi DA, Folkard S, Stutts J, Courtney TK, Connor JK. The link between fatigue and safety. Accid Anal Prev. 2011;34:498-515. http://dx.doi.org/10.1016/j. aap.2009.11.011.

9. Dembe AE, Erickson JB, Delbos RG, Banks SM. The impact of overtime and long work hours on occupational injuries and illnesses: new evidence from the United States. Occup Environ Med. 2005;62:588-97. http://dx.doi.org/10.1136/ oem.2004.016667.
10. Folkard S, Lombardi DA. Modeling the impact of the components of long work hours on injuries and "accidents". Am J Ind Med. 2006;49:953-63. http://dx.doi.org/10.1002/ ajim.20307.

11. Hänecke K, Tiedemann S, Nachreiner F, Grzech-Sukalo H. Accident risk as a function of hour at work and time of day as determined from accident data and exposure models for the German working population. Scand J Work Environ Health. 1998;24 Suppl 3:43-8.

12. Lombardi DA, Folkard S, Willetts JL, Smith GS. Daily sleep, weekly working hours, and risk of work-related injury: US National Health Interview Survey (2004-2008). Chronobiol Int. 2010;27:1013-30. http://dx.doi.org/10.3109/07420528. 2010.489466.

13. Boisard P, Cartron D, Gollac M, Valeyre A. Time and work: duration of work. Luxembourg: Office for Official Publications of the European Communities; 2003.

14. Dembe AE, Delbos R, Erickson JB. The effect of occupation and industry on the injury risks from demanding work schedules. J Occup Environ Med. 2008;50:1185-94. http:// dx.doi.org/10.1097/JOM.0b013e31817e7bf2 .

15. Nakamura K, Shimai S, Kikuchi S, Takahashi H, Tanaka $\mathrm{M}$, Nakano $\mathrm{S}$, et al. Increases in body mass index and waist circumference as outcomes of working overtime. Occup Med (Lond). 1998;48:169-73. http://dx.doi.org/10.1093/ occmed/48.3.169.

16. Rädiker B, Janßen D, Schomann C, Nachreiner F. Extended working hours and health. Chronobiol Int. 2006;23:1305-16. http://dx.doi.org/10.1080/07420520601096245.

17. Breslin FC, Smith P. Age-related differences in work injuries: a multivariate, population-based study. Am J Ind Med. 2005;48:50-6. http://dx.doi.org/10.1002/ajim.20185.

18. Chau N, Mur JM, Touron C, Benamghar L, Dehaene D. Correlates of occupational injuries for various jobs in railway workers: a case-control study. J Occup Health. 2004;46:27280. http://dx.doi.org/10.1539/joh.46.272.

19. Kim J. Psychological distress and occupational injury: findings from the National Health Interview Survey 2000-2003. J Prev Med Public Health. 2008;41:200-7. http://dx.doi. org/10.3961/jpmph.2008.41.3.200.

20. Peele PB, Tollerud DJ. Depression and occupational injury: results of a pilot investigation. J Occup Environ Med. 2005;47:424-7. http://dx.doi.org/10.1097/01. jom.0000158700.50594.0f.

21. Pollack KM, Sorock GS, Slade MD, Cantley L, Sircar K, Taiwo O, et al. Association between body mass index and acute traumatic workplace injury in hourly manufacturing employees. Am J Epidemiol. 2007;166:204-11. http://dx.doi. org/10.1093/aje/kwm058.

22. Smith GS, Wellman HM, Sorock GS, Warner M, Courtney TK, Pransky GS, et al. Injuries at work in the US adult population: contributions to the total injury burden. Am J Public Health. 2005;95:1213-9. http://dx.doi.org/10.2105/ AJPH.2004.049338.

23. Wilkins K, Mackenzie SG. Work injuries. Health Rep. 
2007; 18:25-42.

24. Wirtz A, Lombardi DA, Willetts JL, Folkard S, Christiani DC. A structural equation modeling approach to fatigue-related risk factors for occupational injury. Am J Epidemiol (in press).

25. Brogmus GE. Day of the week lost time occupational injury trends in the US by gender and industry and their implications for work scheduling. Ergonomics. 2007;50:446-74. http:// dx.doi.org/10.1080/00140130601133826.

26. Wong IS, McLeod CB, Demers PA. Shift work trends and risk of work injury among Canadian workers. Scand J Work Environ Health. 2011;37:54-61. http://dx.doi.org/10.5271/ sjweh.3124.

27. Artazcoz L, Cortes I, Borrell C, Escriba-Aguir V, Cascant L. Gender perspective in the analysis of the relationship between long workhours, health and health-related behavior. Scand J Work Environ Health. 2007;33:344-50. http://dx.doi. org/10.5271/sjweh.1154.

28. Rotenberg L, Portela LF, Banks B, Griep RH, Fischer FM, Landsbergis P. A gender approach to work ability and its relationship to professional and domestic work hours among nursing personnel. Appl Ergon. 2008;39:646-52. http://dx.doi. org/10.1016/j.apergo.2008.02.013.

29. Women in Canada: a gender-based statistical report. Ottawa: Statistics Canada; 2005.

30. Fredriksson K, Alfredsson L, Koster M, Thorbjornsson CB, Toomingas A, Torgen M, et al. Risk factors for neck and upper limb disorders: results from 24 years of follow up. Occup Environ Med. 1999;56:59-66. http://dx.doi.org/10.1136/ oem.56.1.59.

31. NCHS. Data file documentation. National Health Interview Survey (NHIS) 2004, 2005, 2006, 2007, 2008, 2009. Hyattsville, MD: National Center for Health Statistics, Center for Disease Control and Prevention; 2009 [2 Dec 2010]; Available from: http://www.cdc.gov/nchs/nhis.htm.

32. Chen LH, Warner M, Fingerhut L, Makuc D. Injury episodes and circumstances: National Health Interview Survey, 19972007. Vital Health Stat 10. 2009:1-55.

33. Pleis JR, Lucas JW. Summary health statistics for U.S. adults: National Health Interview Survey, 2007. Vital Health Stat 10. 2009:1-159.
34. Basner M, Fomberstein KM, Razavi FM, Banks S, William JH, Rosa RR, et al. American time use survey: sleep time and its relationship to waking activities. Sleep. 2007;30:1085-95.

35. Lombardi DA, Wirtz A, Willetts JL, Folkard S. Independent effects of sleep duration and body mass index on the risk of a work-related injury: Evidence from the US National Health Interview Survey (2004-2010). Chronobiol Int. 2012;29 (in press).

36. Kessler RC, Andrews G, Colpe LJ, Hiripi E, Mroczek DK, Normand SL, et al. Short screening scales to monitor population prevalences and trends in non-specific psychological distress. Psychol Med. 2002;32:959-76. http://dx.doi.org/10.1017/ S0033291702006074

37. Jansen N, Kant I, van Amelsvoort L, Nijhuis F, van den Brandt P. Need for recovery from work: evaluating short-term effects of working hours, patterns and schedules. Ergonomics. 2003;46:664-80. http://dx.doi.org/10.1080/0014013031000 085662 .

38. Kling RN, McLeod CB, Koehoorn M. Sleep problems and workplace injuries in Canada. Sleep. 2010;33:611-8.

39. Harel Y, Overpeck MD, Jones DH, Scheidt PC, Bijur PE, Trumble AC, et al. The effects of recall on estimating annual nonfatal injury rates for children and adolescents. Am J Public Health. 1994;84:599-605. http://dx.doi.org/10.2105/ AJPH.84.4.599.

40. Warner M, Schenker N, Heinen MA, Fingerhut LA. The effects of recall on reporting injury and poisoning episodes in the National Health Interview Survey. Inj Prev. 2005;11:282-7. http://dx.doi.org/10.1136/ip.2004.006965.

41. McMenamin T. A time to work: recent trends in shift work and flexible schedules. Mon Labor Rev. 2007;December:3-15.

42. Vegso S, Cantley L, Slade M, Taiwo O, Sircar K, Rabinowitz $\mathrm{P}$, et al. Extended work hours and risk of acute occupational injury: A case-crossover study of workers in manufacturing. Am J Ind Med. 2007;50:597-603. http://dx.doi.org/10.1002/ ajim.20486.

Received for publication: 29 August 2011 